\title{
Easy Access to Modified Cyclodextrins via an Intramolecular Radical Approach
}

\author{
Dimitri Alvarez-Dorta, ${ }^{[a]}$ Elisa I. León, ${ }^{[a]}$ Alan R. Kennedy, ${ }^{[b]}$ Angeles Martín, ${ }^{[a]}$ Inés Pérez-Martín, ${ }^{[a]}$ \\ Ernesto Suárez ${ }^{*[a]}$
}

Abstract: A simple methodology to modify the primary face of cyclodextrins (CDs) is described. The $6{ }^{\prime}-O-y l$ radical of $\alpha-, \beta-$, and $\gamma-$ $\mathrm{CD}$ abstracts regioselectively the $\mathrm{H} 5^{\prime \prime}$, located in the adjacent $\mathrm{D}$ glucose unit, by an intramolecular 1,8-hydrogen atom transfer reaction through a geometrically restricted nine-membered transition state to give a stable 1,3,5-trioxocane ring. The reaction has been extended to 1,4-diols of $\alpha$ - and $\beta-C D$ to give the corresponding bistrioxocanes. The $C_{2}$-symmetric bis-trioxocane corresponding to $\alpha$ $\mathrm{CD}$ is a stable crystalline solid whose structure was confirmed by $\mathrm{X}$ ray diffraction analysis. The calculated geometric parameters confirm that the primary face is severely distorted toward a narrower elliptical shape for this rim.

The design of nanosystems as novel drug carrier systems that allow controlled release is currently a topic of great relevance in medical research to treat a wide variety of diseases, including cancer therapy. ${ }^{[1]}$ In this regard, cyclodextrins (CDs) are of interest as nanocarriers because of their ability to encapsulate biomolecules. ${ }^{[2]}$ These naturallyoccurring macrocyclic oligosaccharides composed of 1,4- $\alpha$-linked glucose units are conical in shape and have an internal cavity creating a hydrophobic microenvironment, while the outside is hydrophilic due to the presence of the hydroxyl groups. ${ }^{[3]}$ These properties are responsible for their aqueous solubility and ability to form host-guest or inclusion complexes with a wide range of molecules, making them one of the most important supramolecular host families. These features illustrate the potential utility of CDs as drug- and gene-delivery vehicles, ${ }^{[4]}$ enzyme mimics, ${ }^{[5]}$ or catalysis, ${ }^{[6]}$ among others.

Native CDs are rarely well-suited to pharmaceutical applications, so their modification is necessary to tune their chemo-physical

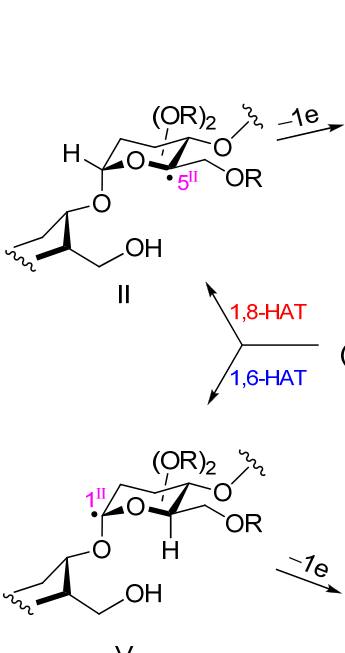

$\mathrm{V}$ efficient and selective chemical modifications have been carried out by allowing for instance grafting substituents to different positions to access amphiphilic $C D,{ }^{[7]}$ and hence to fascinating molecular architectures. ${ }^{[8]}$ It is also worthwhile to mention the synthetic reports that generate significant changes in the cavity shape by altering the conformation of glucose residues. ${ }^{[9]}$ Despite the great deal of methodologies employed, radical processes are practically unknown in these macromolecules because in simple carbohydrates they mostly involve the anomeric position, which is committed in the cyclic $C D$ structure ${ }^{[10]}$ In fact, we have found a single example in the literature concerning intermolecular radical attack on CDs and it is based in EPR experiments with reactive oxygen-centered free radicals generated in aqueous solutions. ${ }^{[11]}$ properties such as to enhance their solubility, change the size cavity or improve their complexing ability. Taking advantage of the different accessibility and reactivity of the hydroxyl groups,

[a] Dr. D. Alvarez-Dorta, Dr. E. I. León, Dr. A. Martín, Dr. I. PérezMartín, Prof. Dr. E Suárez

Síntesis de Productos Naturales

Instituto de Productos Naturales y Agrobiología del CSIC

Carretera de la Esperanza 3, 38203, La Laguna, Tenerife (Spain)

E-mail: angelesmartin@ipna.csic.es esuarez@ipna.csic.es

[b] Dr. A. R. Kennedy

WestCHEM Department of Pure and Applied Chemistry University of Strathclyde

295 Cathedral Street, Glasgow G1 1XL, Scotland (UK)

Supporting information for this article is available on the WWW under http://dx.doi.org/10.1002/anie.201412300.

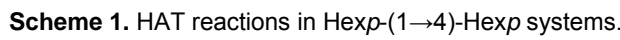

As part of our ongoing research program on radical chemistry in carbohydrates, we have recently described a novel 1,8-hydrogen atom transfer reaction (1,8-HAT) between the two pyranose units in $\mathrm{Hexp}-(1 \rightarrow 4)-\mathrm{Hexp}$ disaccharide systems through a nine-membered transition state (TS). ${ }^{[12]}$ The process is initiated by a primary $6^{\prime}-O-y l$ radical (I) generated under oxidative conditions, which abstracts regioselectively the hydrogen at $\mathrm{C}^{\mathrm{II}}$ to give a C5-radical (II) which, after oneelectron oxidation, collapses into the 1,3,5-trioxocane (IV) via an oxacarbenium ion intermediate (III) (Scheme 1). Alternatively, the $6^{\prime}-\mathrm{O}$-yl radical (I) may abstract the $\mathrm{H} 1^{\prime \prime}$ through a sevenmembered TS to generate a C1-radical (V) which finally stabilizes via the oxacarbenium $(\mathrm{VI})$ to give the spiro ortho ester (VII). We have demonstrated that this regioselectivity is not only 
dependent on the configuration of the four chiral centers implicated in the cyclization step $\left(\mathrm{C} 5^{\prime \prime}, \mathrm{C} 1^{\prime \prime}, \mathrm{C} 4^{\prime}\right.$, and $\left.\mathrm{C} 5^{\prime}\right)$ but also on the conformations of the glycosidic $\left(\Phi=\mathrm{H} 1^{\prime \prime}-\mathrm{C} 1^{\prime \prime}-\mathrm{O} 4^{\prime}-\right.$ $\left.\mathrm{C} 4^{\prime}\right)$ and aglyconic $\left(\Psi=\mathrm{C} 1^{\prime \prime}-\mathrm{O} 4^{\prime}-\mathrm{C} 4^{\prime}-\mathrm{H} 4^{\prime}\right)$ bonds.
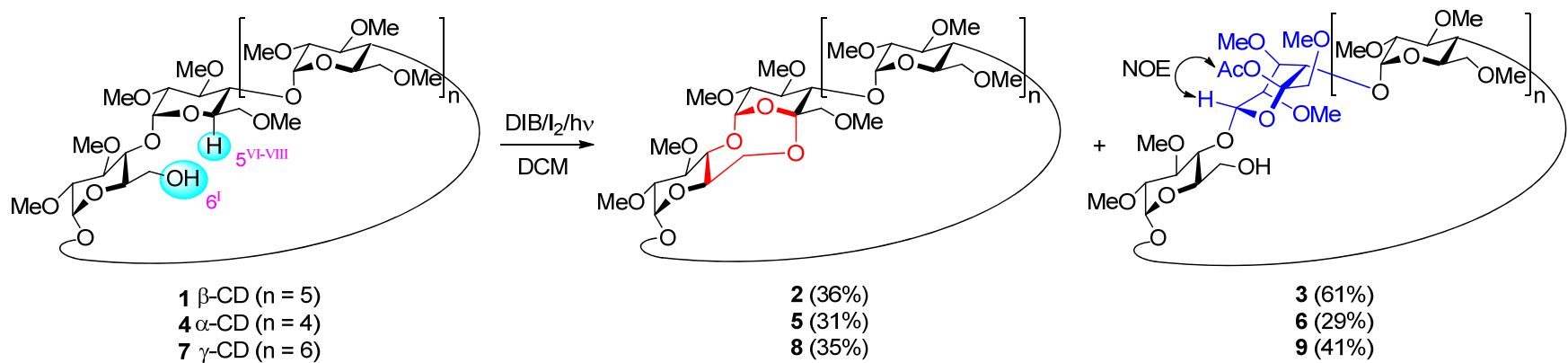

Scheme 2. 1,8-HAT for $6^{\prime}-$ ol- $\alpha-C D$ 1, $6^{\prime}-$ ol- $\beta$-CD 4, and 6'-ol- $\gamma-C D$ 7. DIB = (diacetoxyiodo)benzene.

In a disaccharide with an arrangement of $\alpha$-D-Glcp- $(1 \rightarrow 4)-\beta$ D-GIcp ( $\beta$-maltose) the 6 - $-O$-yl radical abstracts exclusively the $\mathrm{H} 5^{\text {"l }}$ to give a trioxocane ring in a stable boat-chair conformation. ${ }^{[12 a]}$ In the 1,8-HAT TS involved, the glycosidic bond adopts an exo-syn conformation with torsion angles $(\Phi=-$ 32.7, $\Psi=-37.3^{\circ}$ ) leading to an ideal distance of $3.1 \AA$ between the alkoxyl radical and the abstractable $\mathrm{H} 5$ ". We wondered whether this radical methodology might be suitably deployed for the remote functionalization in more complex carbohydrate systems such as CDs, where the D-glucose units are linked in a similar fashion (cyclo-[ $\left.\alpha-D-G l c p-(1 \rightarrow 4)]_{n}\right)$. Preliminary observations made on the $X$-ray structure of permethylated $\beta-C D$ show that the macrocyclic ring has sufficient interresidue flexibility to permit the glycosidic and aglyconic bonds adopt an exo-syn conformation with values of $\Phi$ and $\Psi$ similar to $\beta$ maltose. ${ }^{[13]}$ Analogous situation is obtained over a minimized structure of permethylated $\beta-C D$ and therefore, we consider that the 1,8-HAT process between two vicinal units could take place with high regioselectivity. ${ }^{[14]}$ If this strategy succeeded, it could provide facile access to modified CDs on their primary face, which are difficult to obtain by conventional methods, and which could show significant deformations in their cavities.

In order to test the viability of the radical process, we initiated our investigations by preparing $2^{I-V I I}, 3^{I-V I I}, 6^{I I-V I I}-$ icosa-Omethyl- $\beta-C D \quad(\mathbf{1}),{ }^{[15]}$ according to a three-steps literature procedure, where all the hydroxyl groups, with the exception of a primary one, have been transformed into methyl ethers, since these protecting groups usually lead to an increase in solubility both in water and in organic solvents (Scheme 2). ${ }^{[16]}$ Excitingly, when we treated the alcohol 1 with (diacetoxyiodo)benzene (DIB) (2.2 equiv) and $I_{2}$ (1 equiv) under irradiation with visible light at $30^{\circ} \mathrm{C}$, it was found that the reaction proceeded very fast, with complete consumption of starting material after 30 minutes, to give two main products in near quantitative overall yield: the expected trioxocane derivative $2(36 \%)$ together with the acetate $3(61 \%)$ as the major compound. A minor side reaction involving a competitive intermolecular addition of external nucleophilic acetate ion coming from the reagent to the oxacarbenium ions has also occasionally been observed in disaccharide systems. ${ }^{[12 a, 14]}$ If we decreased the temperature or the equivalents of DIB or $\mathrm{I}_{2}$, the reaction became slower and did not go to completion. However, when we increased the reaction time or the amount of DIB and $I_{2}$, the trioxocane 2 was obtained in $60 \%$ yield as the only product.

The NMR data of $\mathbf{2}$ clearly indicate that oxidation has taken place at $\mathrm{C} 55^{\mathrm{VII}}$. Accordingly, the presence of seven anomeric carbons in the range of $\delta$ 96.97-99.39 ppm and the HMBC correlation of $\mathrm{H}^{\mathrm{VII}}$ proton signal at $\delta_{\mathrm{H}} 5.06 \mathrm{ppm}$ with the $\mathrm{C}^{\mathrm{VII}}$ quaternary carbon atom ( $\delta c 101.04 \mathrm{ppm}$ ) confirm the formation of the trioxocane moiety. Moreover, all D-glucopyranose units are in ${ }^{4} C_{1}$ chair conformations as can be deduced from the values of the coupling constants of the anomeric hydrogens $\left(J_{1,2}\right.$ $\approx 3.6 \mathrm{~Hz}$ ).

On the other hand, the acetate group at $\mathrm{C} 5^{\mathrm{VII}}$ of 3 could be clearly established by $2 \mathrm{D} \mathrm{HSQC}$ and HMBC experiments, whereas the observed deshielding of the ring hydrogens in this unit VII and the values of their coupling constants $\left(J_{1,2}=1.9, J_{2,3}\right.$ $=2.5, J_{3,4}=1.9 \mathrm{~Hz}$ ), determined on the basis of 1D TOCSY experiments, deviate considerably from those of the normal ${ }^{4} C_{1}$ chair and were more consistent with a ${ }^{1} C_{4}$ chair conformation. The stereochemistry of the quaternary $C 5^{\mathrm{VII}}$ was tentatively assigned as $R$ on the basis of NOE interaction between $\mathrm{H} 1^{\mathrm{VII}}$ and the methyl of the acetate group. These results suggest that the nucleophilic attack of the acetate proceeded with inversion of configuration at $\mathrm{C} 5^{\mathrm{VII}}$ and consequently the original $\alpha$-Dglucopyranose unit has been transformed into a $\beta$-L-idopyranose adopting a ${ }^{1} C_{4}$ chair conformation. It is evident that both products are formed by the same $\mathrm{C} 5^{\mathrm{VII}}$ radical intermediate promoted by the alkoxyl radical through an intramolecular 1,8HAT process, no products functionalized at $\mathrm{C}^{\mathrm{VII}}$ via the alternative 1,6-HAT reaction were detected. As far as we know, the presence of a sugar unit with a structure of $\beta$-L-idopyranose as part of a $\beta-C D$ ring has no literature precedent. 


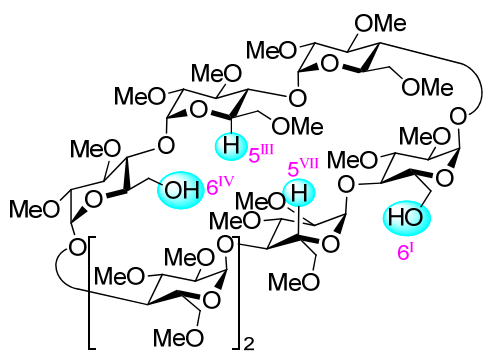

$106^{\mathrm{l}, \mathrm{IV}}$-diol- $\beta-\mathrm{CD}$

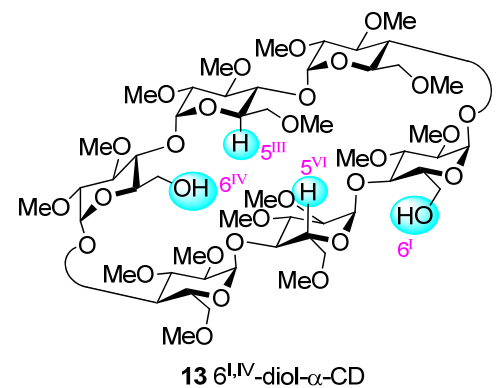

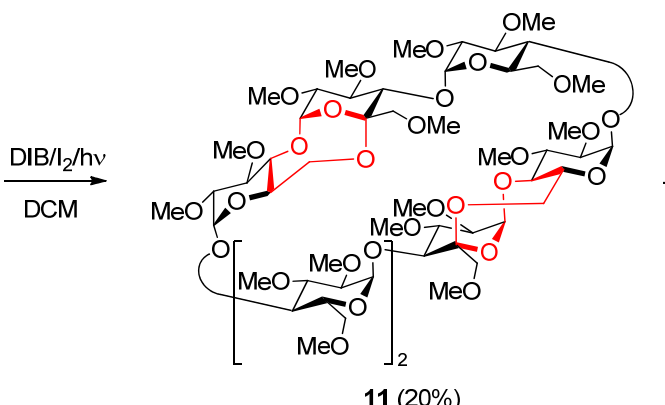
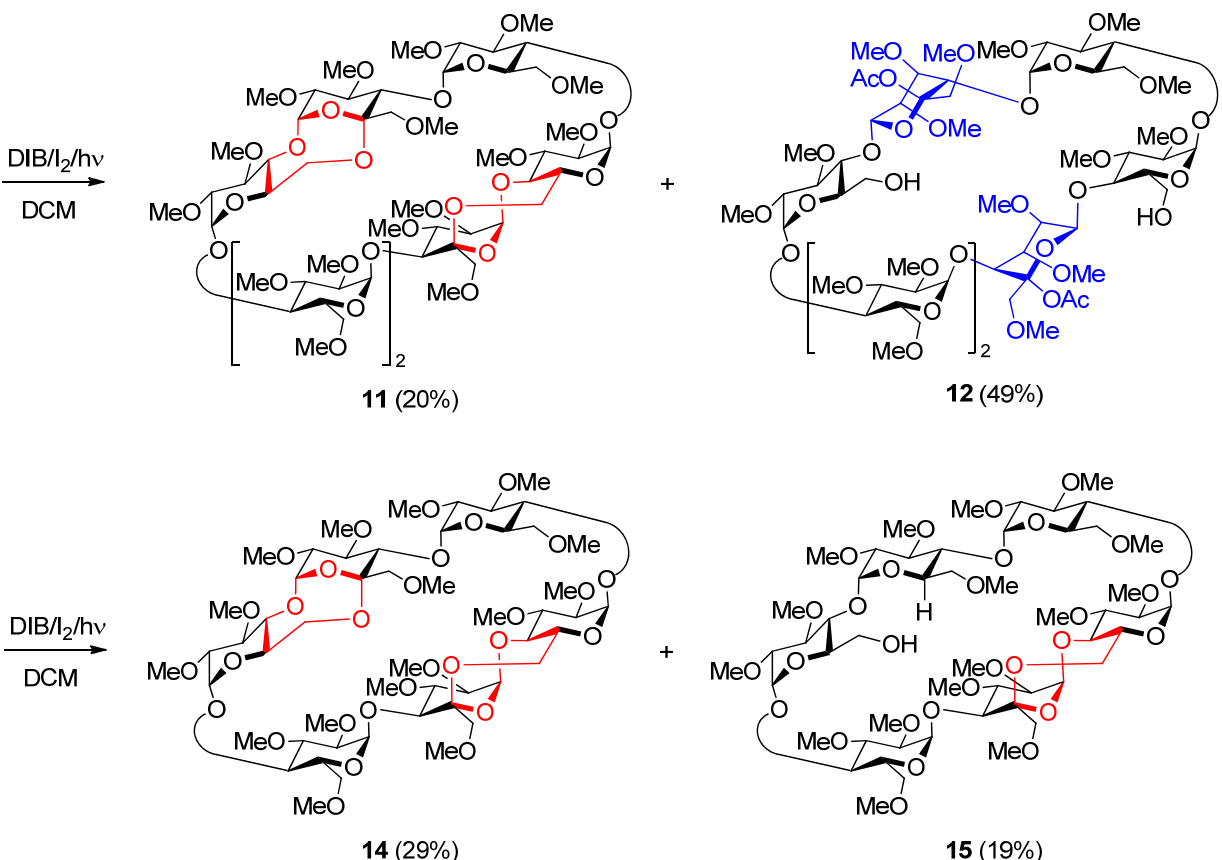

Scheme 3. 1,8-HAT for $6^{\mathrm{l}, \mathrm{IV}}$-diol- $\beta$-CD 10 and $6^{\mathrm{l}, \mathrm{IV}}$-diol- $\alpha-$ CD 13. DIB = (diacetoxyiodo)benzene.

Encouraged by these preliminary results, we decided to extend the reaction to the monoalcohols derived from $\alpha$ - and $\gamma$ $\mathrm{CD}, 4^{[17]}$ and $7^{[18]}$ respectively, which were prepared following the same procedure applied to the 6 -ol- $\beta-C D$ derivative. Pleasingly, both compounds behaved in an analogous manner to the $\beta-C D$ derivative albeit generating the corresponding trioxocane derivatives 5 and 8 and acetates $\mathbf{6}$ and $\mathbf{9}$, in somewhat lower overall yields (Scheme 2). We soon realized that acetates 6 and 9 were undergoing complete hydrolysis during the standard purification process, giving exclusively the trioxocane derivatives $\mathbf{5}$ and $\mathbf{8}$, respectively, and this is most likely responsible for the lower yield observed. Notwithstanding, pure acetates 6 and 9 were obtained avoiding the typical aqueous workup and after careful flash column chromatography using silica gel scraped from commercial coated TLC plates (see Supporting Information). On the contrary, the trioxocane derivatives are stable for extended periods of time at room temperature.

The structures and conformations of the acetyl-derivatives 6 and 9 were analogously confirmed by 1D TOCSY and 2D HSQC and $\mathrm{HMBC}$ experiments. Of particular relevance are the differences observed in the conformation of unit $\mathrm{VI}$ of compound 6 by changing the solvent from $\mathrm{CDCl}_{3}$ to $\mathrm{C}_{6} \mathrm{D}_{6}$. Thus, in $\mathrm{CDCl}_{3}$ small coupling constants were noted in the 1D TOCSY experiment, between all the vicinal ring protons $\left(J_{1,2}=2.8, J_{2,3}=\right.$ $\left.3.2, \quad J_{3,4}=2.8 \mathrm{~Hz}\right)$ suggesting predominantly a ${ }^{1} C_{4}$ chair conformation while in $\mathrm{C}_{6} \mathrm{D}_{6}$ these values $\left(J_{1,2}=3.5, J_{2,3}=8.5\right.$, $J_{3,4}=7.9 \mathrm{~Hz}$ ) preferentially point to a ${ }^{4} C_{1}$ conformation. These observations are in contrast with the acetates derived from $\beta$ and $\gamma-\mathrm{CD}, 3$ and 9 respectively, which show the same ${ }^{1} C_{4}$ conformation in both solvents.
To assess the versatility and scope of this methodology we have investigated the feasibility of applying the same procedure to 1,4-diols of $\beta$ - and $\alpha-C D$ to determine whether the two hydroxyl groups can participate in two 1,8-HAT reactions simultaneously. The reaction of the $6^{\mathrm{I}, \mathrm{IV}}$-diol- $\beta-C D$ derivative $10^{[15 a]}$ with DIB (3 equiv) and $I_{2}$ (1.7 equiv) afforded four products in good overall yield, bis-trioxocane compound 11 (20\%), bisacetyl-derivative 12 as the major product $(49 \%)$ and a mixture of monotrioxocane-monoacetyl derivatives (14\%) (not shown, see the Supporting Information) which could be transformed into 11 after treatment with iodine (Scheme 3). The NMR characteristics of 12 clearly indicate that the introduction of both acetates in the corresponding D-glucose units III and VII has taken place with inversion of configuration at C5. Accordingly, the deshielding of the hydrogens of these units and their small coupling constants $(J \approx 1.9-2.5 \mathrm{~Hz}$ ) confirmed the presence of two $\beta$-L-idopyranose units both in ${ }^{1} C_{4}$ chair conformations. Moreover, the NOE experiments show interaction between $\mathrm{H} 1^{\mathrm{VII}}$ or $\mathrm{H} 1^{11 \mathrm{II}}$ and the respective methyl of the acetate group, tentatively establishing the absolute configuration at $\mathrm{C} 5^{\mathrm{VII}}$ and $\mathrm{C} 5^{\mathrm{III}}$ as $R$.

Finally, we carried out the reaction with $6^{1, I V}$-diol- $\alpha-C D$ derivative 13. ${ }^{[17,19]}$ The bis- and mono-trioxocanes 14 and 15 were the only compounds obtained in the reaction, no product from the incorporation of acetate in the molecule being detected, revealing the greater steric hindrance in this hexamer (Scheme 3 ). The structures of both products were determined by $1 \mathrm{D}$ and 2D NMR experiments. Furthermore, compound $\mathbf{1 4}$ is a stable crystalline solid whose structure was unambiguously confirmed by X-ray crystallographic analysis, showing two 1,3,5-trioxocane rings in boat-chair conformations with a guest $n$-hexane molecule as an inclusion complex into the CD cavity (Figure 
1). ${ }^{[20]}$ As expected, the NMR spectra are consistent with the $C_{2^{-}}$ symmetry of the proposed structure.

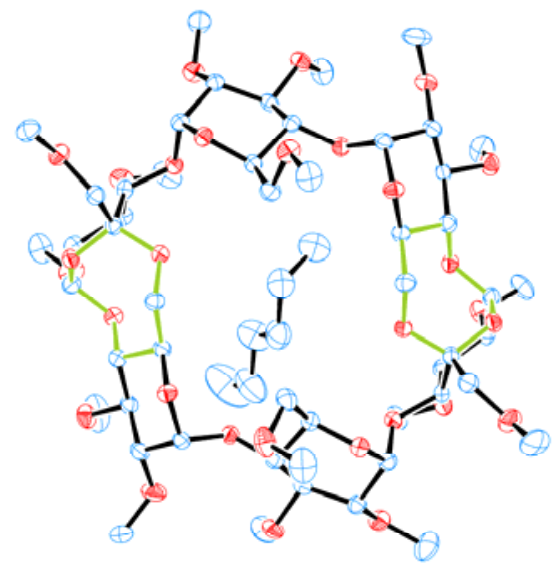

Figure 1. X-Ray crystal structure of compound 14. $\mathrm{C}$ blue, $\mathrm{O}$ red, $\mathrm{H}$ atoms not shown. Thermal ellipsoids drawn at $50 \%$ probability.

The comparison of the geometrical parameters of compound 14 with those of the related permethylated $\alpha-C D^{[21]}$ shows that the presence of the two 1,3,5-trioxocane rings does not significantly alter the secondary face of the molecule (see the Supporting Information, Tables S2 and S3). Thus, for instance, the distances and angles between the six interglycosidic oxygen atoms $\left(04^{n}\right)$, as well as the radii of the gravity center of the hexagon formed by these $\mathrm{O} 4^{\mathrm{n}}$ oxygens are quite similar in both $X$-ray structures. Nor do the trioxocane rings seem to affect the ${ }^{4} C_{1}$ chair geometries of the six glucose units, as shown with the Cremer-Pople puckering parameters which describe slightly distorted chairs similar to those found in the permethylated $\alpha$ $C D .^{[22]}$ The most significant differences are observed in the tilt angles made by the $\mathrm{O} 4^{\mathrm{n}}$ mean plane and the mean planes through the glucose units principally in residues $I$ and $V$ adjacent to the trioxocane rings.

However, the trioxocane rings severely distort the primary face of the molecule. This is clearly observed when comparing the geometrical parameters of the irregular hexagon comprised by the side chain carbon atoms $\left(\mathrm{C}^{\mathrm{n}}\right)$ which points towards a much narrower elliptical shape for this rim (see the Supporting Information, Tables S2 and S3).

In summary, the remote $\mathrm{C}-\mathrm{H}$ functionalization initiated by 6 $O-y l$ radicals proceeds with complete regioselectivity in $\alpha-, \beta-$, and $\gamma$-cyclodextrin models, due to very suitable geometrical requirements which favour the TS of an intramolecular 1,8-HAT process between two contiguous units of the macromolecule. To the best of our knowledge, this is the first time that a radical approach is applied to access modified CDs with significant deformations in the primary face. The mild conditions and high efficiency are the key features of this procedure with potential synthetic and pharmaceutical applications. The possibility to apply this methodology not only to monoalcohols but also to $1,4-$ diols and carry out two 1,8-HAT processes simultaneously, opens the way to generate more complex CD systems. Work in this sense is now in progress and will be reported in due course.

\section{Acknowledgements}

Financial support by the Investigation Programs of the Ministerio de Economía y Competitividad (CTQ2010-18244) and the COST Action CM1201 "Biomimetic Radical Chemistry" is acknowledged. D.A.-D. thanks the Ministerio de Economía y Competitividad for a fellowship. We wish to thank Dr. Shinya Fushinobu (University of Tokyo, http://www.ric.hiho.ne.jp/asfushi/) for access to the Cremer-Pople parameter calculator.

Keywords: Cyclodextrins $\bullet$ Radical reactions $\bullet$ Hydrogen transfer $\bullet$ Trioxocane $\bullet$ Host-guest systems

[1] a) Cancer Targeted Drug Delivery, (Eds. Y. H. Bae, R. J. Mrsny, K. Park), Springer, New York, 2013; b) S. Sultana, M. R. Khan, M. Kumar, S. Kumar, M. Ali, J. Drug Target. 2013, 21, 107-125.

[2] a) J. M. Myrick, V. K. Vendra, S. Krishnan, Nanotechnol. Rev. 2014, 3, 319-346; b) F. J. Otero-Espinar, J. Blanco-Méndez, (Eds.) Curr. Top. Med. Chem. 2014, 14, 463-551.

[3] For reviews on cyclodextrins, see: a) Z. V. Todres in Organic Chemistry in Confining Media, Springer, Switzerland, 2013, chap. 1, pp. 1-63; b) F. Davis, S. Higson, Macrocycles: Construction, Chemistry and Nanotechnology Applications, John Wiley \& Sons, 2011, pp. 190-254; c) Cyclodextrins and Their Complexes, (Ed. H. Dodziuk), Wiley-VCH: Weinheim, 2006; d) V. T. D'Souza, K. B. Lipkowitz (Eds.) Chem. Rev. 1998, 98, 1741-2076.

[4] a) J. Rodríguez-Lavado, M. de la Mata, J. L. Jiménez-Blanco, M. I. García-Moreno, J. M. Benito, A. Díaz-Quintana, J. A. Sánchez-Alcázar, K. Higaki, E. Nanba, K. Ohno, Y. Suzuki, C. Ortiz Mellet, J. M. García Fernández, Org. Biomol. Chem. 2014, 12, 2289-2301; b) C. Ortiz Mellet, J. M. García Fernández, J. M. Benito, Chem. Soc. Rev. 2011 40, 1586-1608; c) C. Ortiz Mellet, J. M. Benito, J. M. García Fernández, Chem. Eur. J. 2010, 16, 6728-6742; d) A. L. Laza-Knoerr, R. Gref, P. Couvreur, J. Drug Target. 2010, 18, 645-646.

[5] a) C. M. Pedersen, M. Bols, in Organic Synthesis and Molecular Engineering (Ed.: M. B. Nielsen), John Wiley \& Sons, Hoboken, NJ, 2013, pp. 305-332; b) Y. Zhou, C. M. Pedersen, M. Bols, Tetrahedron Lett. 2013, 54, 2458-2461; c) Y. Zhou, L. Marinescu, C. M. Pedersen, M. Bols, Eur. J. Org. Chem. 2012, 6383-6389; d) R. Breslow in Artificial Enzymes, Wiley-VCH, Weinheim, 2005.

[6] a) K. Kanagaraj, K. Pitchumani, J. Org. Chem. 2013, 78, 744-751; b) L. Liang, A. K. Diallo, L. Salmon, J. Ruiz, D. Astruc, Eur. J. Inorg. Chem. 2012, 2950-2958; c) J. D. Senra, L. F. B. Malta, L. C. S. Aguiar, A. B. C. Simas, O. A. C. Antunes, Curr. Org. Chem. 2010, 14, 1337-1355; d) F. Hapiot, S. Tilloy, E. Monflier, Chem. Rev. 2006, 106, 767-781.

[7] For a recent review on modified cyclodextrins synthesis, see: a) S. Guieu, M. Sollogoub in Modern Synthetic Methods in Carbohydrate Chemistry: From Monosaccharides to Complex Glycoconjugates (Eds.: D. B. Werz, S. Vidal), Wiley-VCH, Weinheim, 2013, pp. 241-283; For other recent examples not included previously, see: b) L. GallegoYerga, M. J. González-Álvarez, N. Mayordomo, F. Santoyo-González, J. M. Benito, C. Ortiz Mellet, F. Mendicuti, J. M. García Fernández, Chem. Eur. J. 2014, 20, 6622-6627; c) P. Balbuena, R. Gonçalves-Pereira, J. L. Jiménez Blanco, M. I. García-Moreno, D. Lesur, C. Ortiz Mellet, J. M. García Fernández, J. Org. Chem. 2013, 78, 1390-1403; d) S. Xiao, M. Yang, F. Yu, L. Zhang, D. Zhou, P. Sinaÿ, Tetrahedron 2013, 69, 40534060; e) P. Zhang, A. Wing, L. Cui, C.-C. Ling, Org. Lett. 2012, 14 
1612-1615; f) R. Ghosh, P. Zhang, A. Wang, C.-C. Ling, Angew. Chem. 2012, 124, 1580-1584; Angew. Chem., Int. Ed. 2012, 51, 1548-1552.

[8] a) L. Zerkoune, A. Angelova, S. Lesieur, Nanomaterials 2014, 4, 741 765; b) L. Gallego-Yerga, M. Lomazzi, F. Sansone, C. Ortiz Mellet, A Casnati, J. M. García Fernández, Chem. Commun. 2014, 50, 74407443; c) E. Engeldinger, D. Armspach, D. Matt, Chem. Rev. 2003, 103 4147-4173; d) F. Sallas, R. Darcy, Eur. J. Org. Chem. 2008, 957-969.

[9] a) H. J. Lindner, D.-Q. Yuan, K. Fujita, K. Kubo, F. W. Lichtenthaler, Chem. Commun. 2003, 1730-1731; b) G. Gattuso, S. A. Nepogodiev J. F. Stoddart, Chem. Rev. 1998, 98, 1919-1958; c) P. R. Asthon, G Gattuso, R. Königer, J. F. Stoddart, D. J. Williams, J. Org. Chem. 1996 61, 9553-9555; d) H. Yamamura, H. Nagaoka, M. Kawai, Y. Butsugan, H. Einaga, Chem. Commun. 1996, 1069-1070; e) P. R. Asthon, S. E. Boyd, G. Gattuso, E. Y. Hartwell, R. Königer, N. Spencer, J. F. Stoddart J. Org. Chem. 1995, 60, 3898-3903; f) A. Gadelle, J. Defaye, Angew. Chem. 1991, 103, 94-95; Angew. Chem., Int. Ed. Engl. 1991, 30, 78$80 ;$ g) I. Ikeda, Y. Nagano, Y. Du, T. Ikeda, F. Toda, Tetrahedron Lett. 1990, 31, 5045-5048.

[10] I. Pérez-Martín, E. Suárez in Encyclopedia of Radicals in Chemistry, Biology and Materials, Vol. 2 (Eds.: C. Chatgilialoglu, A. Studer), John Wiley \& Sons Ltd, Chichester, 2012, pp. 1131-1174.

[11] B. C. Gilbert, J. R. L. Smith, P. Taylor, S. Ward, A. C. Whitwood, J. Chem. Soc., Perkin Trans. 2 2000, 2001-2007.

[12] a) C. G. Francisco, A. J. Herrera, A. R. Kennedy, A. Martín, D. Melián, I. Pérez-Martín, L. M. Quintanal, E. Suárez, Chem. Eur. J. 2008, 14 10369-10381; b) A. Martín, I. Pérez-Martín, L. M. Quintanal, E. Suárez, Org. Lett. 2007, 9, 1785-1788; c) C. G. Francisco, A. J. Herrera, A. R. Kennedy, D. Melián, E. Suárez, Angew. Chem. 2002, 114, 884-886 Angew. Chem. Int. Ed. 2002, 41, 856-858; For a very recent review on HAT, see: d) M. Nechab, S. Mondal, M. P. Bertrand, Chem. Eur. J. 2014, 20, 16034-16059.
[13] T. Steiner, W. Saenger, Angew. Chem. 1998, 110, 3628-3632; Angew. Chem. Int. Ed. 1998, 37, 3404-3407.

[14] E. I. León, A. Martín, I. Pérez-Martín, L. M. Quintanal, E. Suárez, Eur. J. Org. Chem. 2010, 5248-5262.

[15] a) Z. Chen, J. S. Bradshaw, Y.-F. Shen, Y. Habata, M. L. Lee, J. Org Chem. 1997, 62, 8529-8534; b) Z. Chen, J. S. Bradshaw, M. L. Lee Tetrahedron Lett. 1996, 37, 6831-6834; c) G. Yi, J. S. Bradshaw, B. E. Rossiter, A. Malik, W. Li, M. L. Lee, J. Org. Chem. 1993, 58, 4844 4850; For other procedures for the synthesis of mono- and dihydroxypermethylated CDs, see: d) T. Lecourt, J.-M. Mallet, P. Sinaÿ, Carbohydr. Res. 2003, 338, 2417-2419; e) B. du Roizel, J.-P. Baltaze P. Sinaÿ, Tetrahedron Lett. 2002, 43, 2371-2373; f) T. Kaneda, T. Fujimoto, J. Goto, K. Asano, Y. Yasufuku, J. H. Jung, C. Hosono, Y. Sakata, Chem. Lett. 2002, 514-515; g) M. Tanaka, Y. Kawaguchi, T. Niinae, T. Shono, J. Chromatogr. 1984, 314, 193-200.

[16] a) E. Sabadini, F. C. Egídio, F. Y. Fujiwara, T. Cosgrove, J. Phys. Chem. B 2008, 112, 3328-3332; b) A. Kusmin, R. E. Lechner, M. Kammel, W. Saenger, J. Phys. Chem. B 2008, 112, 12888-12898.

[17] T. H. Fenger, J. Bjerre, M. Bols, ChemBioChem 2009, 10, 2494-2503.

[18] T. Chaise, P. Cardinael, S. Tisse, J.-C. Combret, J.-P. Bouillon, Tetrahedron: Asymmetry 2008, 19, 348-357.

[19] L. Kumprecht, M. Budesinsky, P. Bour, T. Kraus, New J. Chem. 2010 34, 2254-2260.

[20] CCDC 1039442 contains the supplementary crystallographic data for this paper. These data can be obtained free of charge from The Cambridge Crystallographic Data Centre via www.ccdc.cam.ac.uk/data_request/cif.

[21] T. Steiner, W. Saenger, Carbohydr. Res. 1996, 282, 53-63. Crystallographic data were obtained by courtesy of The Cambridge Crystallographic Data Centre (Database code CSD = TEVCEC).

[22] D. Cremer, J. A. Pople, J. Am. Chem. Soc. 1975, 97, 1354-1358. 


\section{Entry for the Table of Contents}

\section{COMMUNICATION}

Successful match of cyclodextrins with radical chemistry. The bi-alkoxyl radical generated from $6^{1, I V}$-diol- $\alpha-C D$ under oxidative conditions led to a stable crystalline bis-1,3,5-trioxocane with a guest $n$-hexane molecule where the primary face is severely distorted toward a narrower elliptical shape.

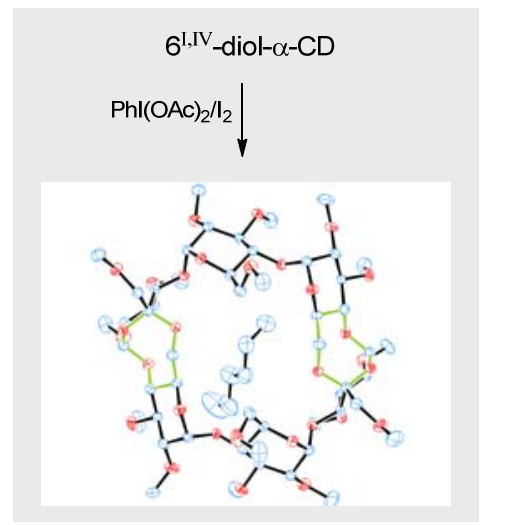

Dimitri Alvarez-Dorta, Elisa I. León, Alan R. Kennedy, Angeles Martín, * Inés Pérez-Martín, Ernesto Suárez*

Page No. - Page No.

Easy Access to Modified Cyclodextrin Systems via an Intramolecular Radical Approach 